\title{
Mathematics Perceptions of Pre-service Elementary School Teachers
}

\author{
Yea-Ling Tsao \\ Minnesota State University, Mankato, USA
}

\begin{abstract}
The purpose of this study is to explore what mathematics perceptions are held by pre-service teachers. Sixty-eight pre-service elementary school teachers enrolled in a mathematics content course for elementary school teachers completed Mathematics Perceptions Survey (MPS) to measure their mathematics perceptions. All items were presented in the form of a 7-point rating scale. The questionnaire contained questions related to pre-service teachers' perceptions of what mathematics is and how to do well in it, what mathematics solutions should be, how mathematics problems can be solved, how mathematics should be taught, and how mathematics is learned, mathematics genius to do mathematics, the nature of school mathematics, and student motivation. Findings indicated that the beliefs pre-service elementary school teachers reflected in the instrument items were in line with the current reform movements in mathematics education. The pre-service elementary school teachers generally indicated positive beliefs to the questionnaire items about mathematics. For instance, they gave importance to appreciate developing different ways of solutions to the same problem, why a solution to a mathematics problem works, think in mathematics can be creative and discover things by themselves, and apply mathematics knowledge and skills to real life. However, the results revealed that the pre-service elementary school teachers held several moderate and negative beliefs. The data indicate that pre-service elementary school teachers' definition of mathematics reflects more of a subject that is all about symbols, numbers, equations, formulas, and procedures that are to be memorized. The results also indicated that pre-service elementary school teachers do not agree that the subject matter is interesting, and that learning the discipline will help them think clearly. Motivation is among the most powerful determinants of students' success or failure in school. These results suggest that mathematics educators need to develop pre-service teachers' motivation towards mathematics; help pre-service teachers understand and value the need for perseverance in solving mathematics problems; and help students realize the connections between the mathematics they learn in school and the mathematics-related fields that might interest them.
\end{abstract}

Keywords: mathematics perceptions, pre-service elementary teachers, problem-solving

\section{Introduction}

What is mathematics and why is it important? Frequently, people reflect back to their vision of school mathematics, some others reflect upon its relevance to the real world. Mathematics is not just about answers and results, but also about strategies and approaches. Mathematics can help anyone learn to think more abstractly, apply logical deduction, visualize three-dimensionally, and develop useful problem-solving skills.

Yea-Ling Tsao, Ph.D., professor, Department of Mathematics and Statistics, Minnesota State University, Mankato. 
Mathematics is essential to such fields as engineering, science, and technology, as well as economics, business, anthropology, sociology, and many more. These are skills and techniques that can benefit people in a variety of non-mathematical disciplines, not just in mathematics. Doing mathematics offers an opportunity to be creative, and to share ideas and opinions. This study explores elementary pre-service teachers' illustrations to this question in order to gain insight into their perceptions of mathematics. The impact of pre-service teachers' perceptions about mathematics and learning is a well-researched problem (Swars, 2006). Pre-service teachers' beliefs towards mathematics seem to be shaped by how they define mathematics, and what they consider the role of mathematics is in their life. But pre-service teachers considering mathematics as symbols and procedures tend to treat their mathematics concepts as a set of memorization facts; in that case, pre-service teachers will not put any effort to understand "whys" and spend time solving problems. In spite of the nature of pre-service teachers' prior experiences in mathematics, those experiences can provide an effective backdrop for developing attitudes towards mathematics teaching and learning aligned with reform recommendations (National Council of Teachers of Mathematics (NCTM), 2000). Thus, it is important that researchers understand what the perceptions are and what influences these perceptions. Many elementary pre-service teachers struggle to understand the meaning behind the mathematics taught. Often this is due to the lack of experience with the content taught in the elementary grades (Ball \& Bass, 2000; Sowder \& Shappelle, 1995). Vinter (1999) found that many prospective teachers bring an abstract, rather than an applied, real world understanding of mathematics and this in turn affects their ability to make the content meaningful for their students. The types of instruction delivered by many elementary teachers provide evidence of this lack of understanding of mathematics applications. This research would help teacher educators explicitly address specific aspects of dispositional issues in mathematics content courses for teaching and create opportunities for exposing pre-service teachers to reform practices tend to positively and reflecting on their strengths and weaknesses to support their learning of mathematics. When mathematics educators understand the link between pre-service teachers' perceptions about the nature of mathematics, mathematics learning, mathematics teaching, and their actual academic performance, then they can create opportunities for exposing pre-service teachers to reform practices tend to positively and reflecting on their strengths and weaknesses of their perceptions.

\section{Background of the Study}

Commonly, mathematics is associated with certainty; knowing it, with being able to get the right answer, quickly (Ball, 1988). Lampert (1990) stated that these cultural assumptions are shaped by school experience, in which doing mathematics means following the rules laid down by the teacher; knowing mathematics means remembering and applying the correct rule when the teacher asks a question; and mathematical truth is determined when the answer is ratified by the teacher. Beliefs about how to do mathematics and what it means to know it in school are acquired through years of watching, listening, and practicing (Lampert, 1990). The beliefs a person holds about his/her ability to do mathematics, about the nature of mathematics, and about problem-solving are dominant forces in shaping that person's behavior while engaged in work on a mathematical task.

Schoenfeld (1989) has been especially influential in developing this line of research, pointing out that students' problem-solving performance was often undermined by their beliefs about mathematics. Prominent examples of such beliefs are that mathematics mainly involves memorizing rules and procedures, and that 
mathematical problems can be solved in just a few minutes or they cannot be solved at all. Belief in mathematics education is an important thread linking a number of studies of both teachers and students. Students' beliefs and perceptions towards mathematics teaching and learning play an important role in mathematics education (McLeod, 1989). Students' learning outcomes are strongly related to their beliefs and attitudes towards mathematics (Schoenfeld, 1992). If a student does not think mathematics is important, then he/she will not again consider his/her mathematics course worthy enough to spend time on. Motivation of these students would be very low. Then, it will be difficult to have pre-service teachers learn mathematics meaningfully and have understanding. This means that one needs to address his/her beliefs and behaviors before introducing mathematical concepts and expecting meaningful learning in class. The research into how pre-service elementary school teachers' mathematics perception affects learning of mathematics-related subjects has been one of the core areas of interest by mathematics educators. A teacher's understandings and perceptions towards mathematics impact the quality of instruction received by his/her students (Hill, Schilling, \& Ball, 2004). Resnick (1987) suggested that many times teachers prepare students to do school mathematics, but this is not the same as mathematics beyond the classroom. Effectively solving mathematics problems beyond the classroom requires one to understand the meaning behind processes, rather than simply memorize algorithms. However, teachers in the United States often perceive the procedural knowledge as the important elements in mathematics and neglect elements such as conceptual knowledge and problem-solving that impact lasting understanding and mathematical thinking (Ma, 2010). Teacher education is one place that can impact this view and begin to change this perception.

There have been a few recent studies reporting negative attitudes towards mathematics mainly among general student population. Existing research indicates that many students hold negative attitude towards mathematics, and a perception of mathematics that is more of a loose collection of facts, rules, procedures, and formulas to be memorized (Battista, 1994; Tobias, 1993). Likewise, others claim the potentially undesired influence of negative attitude and perception on student performance in mathematical tasks, and on their cognition (Garofalo, 1998; Hembree, 1990; Tobias, 1993). Moreover, the NCTM has established affective goals for all mathematics students which include learning to value mathematics and developing confidence, interest, perseverance, and curiosity in learning mathematics. Study of pre-service teachers' mathematics perceptions has helped change the emphasis of educational research "from a behavioral conception of teaching towards a conception that takes account of teachers as rational beings" (Thompson, 1992, p. 142). This has contributed to reform of the educational research agenda. Understanding teaching from a teacher's perspective has enriched the understanding of learning from a student's perspective. However, more research is needed concerning the connections between teacher and student perspectives. These findings led the researcher to undertake a study into the mathematics perceptions of pre-service teachers concerning mathematics and themselves as learners and teachers of mathematics. If pre-service teachers hold certain beliefs about mathematics and themselves which palliate against them teaching mathematics with enthusiasm and real understanding then it is the responsibility of the institution preparing these students for their teaching role to undertake procedures to break the cycle which has developed. Through research on pre-service teachers' perceptions about mathematics and mathematics teaching and learning, teacher educators can learn how best to address these issues with the intention of promoting positive attitudes and beliefs towards mathematics for the teacher education program. 


\section{Methodology}

\section{Participants}

The population of this study consists of pre-service elementary school teachers at a mid-sized, four-year state university in a mid-sized town in the Southern Minnesota. The sample was composed of students in two of three sections of entry level mathematics methods course. Sixty-eight participants from these two classes completed data collection tasks. Among the 68 participants, 15 were male and 53 were female.

\section{Instrument and Procedure}

The Mathematics Perceptions Survey (MPS) containing 39 closed questions was developed by Alan Schoenfeld and was used with his permission in this study. The MPS uses a Likert-type scale wherein the subjects respond, on a scale of 1-7, to their degree of agreement with a statement. The pre-service teachers rated each of the first 33 questions on a 7-point scale, with 1 being "Strongly agree", 4 being "Neutral", and 7 being "Strongly disagree". Table 1 shows a sample of the MPS items. The researcher grouped 31 items into nine categories since the researcher analyzed the questionnaire and found some questions asked the same concept; left item 9 and 25 out of nine categories. The last six questions are concerned with gender, grades, and perceptions of their parents' attitude towards mathematics.

The questionnaire contained questions related to pre-service teachers' perceptions of what mathematics is, how to do well in it, what mathematics solutions should be, how mathematics problems can be solved, how mathematics should be taught, and how mathematics is learned, mathematics genius to do mathematics, nature of school mathematics, and student motivation.

Table 1

Sample of MPS

\begin{tabular}{lll}
\hline Category & Concept & Statements \\
\hline 1 & What mathematics is? & Math is mostly facts and procedures that have to be memorized. \\
2 & How to do well in it? & $\begin{array}{l}\text { Memorizing is one of the most important things in math. } \\
\text { When the teacher asks a question in math class, you have to remember }\end{array}$ \\
3 & What mathematics solutions should be? & $\begin{array}{l}\text { Whe right answer to answer it correctly. } \\
\text { the }\end{array}$ \\
4 & How mathematics problems can be solved? & Math problem can be correctly in only one way. \\
5 & How mathematics should be taught? & $\begin{array}{l}\text { Good math teachers show students lots of different ways to look at the } \\
\text { same question. }\end{array}$ \\
6 & How mathematics is learned? & Students can discover math on their own. \\
7 & Mathematics genius to do mathematics & Some people are good at math and some are not. \\
8 & Natural of school mathematics & School math has nothing to do with the real world. \\
$9 \mathrm{a}$ & Student motivation (positive) & I try to learn math to make the teacher think I am a good student. \\
$9 \mathrm{~b}$ & Student motivation (negative) & I try to learn math because it is required. \\
\hline
\end{tabular}

The last six questions are concerned with gender, grades, and perceptions of their parents' attitude towards mathematics. In the study, the questionnaire was determined to be highly reliable with an alpha of 0.8403. The researcher grouped 31 items into nine categories since the researcher analyzed the questionnaire and found some questions asked the same concept. Table 2 shows nine categories with items of the MPS. On the first day of mathematics content class, these pre-service teachers were given the MPS to evaluate student mathematics perceptions on August 2014. Typically, the questionnaire took only 15-20 minutes to complete. 
Table 2

Nine Categories

\begin{tabular}{lll}
\hline Category & Concept & Contained items \\
\hline 1 & What mathematics is? & $1,2,3$, and 31 \\
2 & How to do well in it? & 14,28, and 32 \\
3 & What mathematics solutions should be? & $4,5,6$, and 15 \\
4 & How mathematics problems can be solved? & $11,12,13$, and 17 \\
5. & How mathematics should be taught? & 7 and 8 \\
6 & How mathematics is learned? & 10,16, and 27 \\
7 & Mathematics genius to do mathematics & 30 and 33 \\
8 & Nature of school mathematics & 26 and 29 \\
$9 \mathrm{a}$ & Student motivation (positive) & $18,20,21$, and 24 \\
$9 \mathrm{~b}$ & Student motivation (negative) & 19,22, and 23 \\
\hline
\end{tabular}

\section{Results and Discussion}

The last six questions are concerned with gender, grades, and perceptions of their parents' attitude towards mathematics. Table 3 shows response of pre-service teachers' grades and perceptions of their parent's attitude towards mathematics. The data indicate approximately $75 \%$ of pre-service elementary school teachers and their parents think that it is important to do well in mathematics. The results confirmed Sam (2002) and McLeod's (1989) research findings that parents' views about mathematics have strong effect on the way they teach their children. They reported the grades they usually get in mathematics class with A (32.8\%), B (51.1\%), and C (16.1\%).

Table 3

Response of Pre-service Teachers' Grades and Perceptions of Their Parents' Attitude Towards Mathematics

\begin{tabular}{|c|c|c|c|c|}
\hline \multirow{2}{*}{ Question } & \multicolumn{4}{|c|}{ Response (\%) } \\
\hline & Very important & Sort of important & Not very important & Not important at all \\
\hline $\begin{array}{l}\text { How important do you think it is to do well } \\
\text { in mathematics? }\end{array}$ & $76.9 \%$ & $21.5 \%$ & $1.1 \%$ & $0.5 \%$ \\
\hline $\begin{array}{l}\text { How important does your mother think it is } \\
\text { for you to do well in mathematics? }\end{array}$ & $74.2 \%$ & $23.1 \%$ & $1.1 \%$ & $1.6 \%$ \\
\hline \multirow[t]{3}{*}{$\begin{array}{l}\text { How important does your farther think it is } \\
\text { for you to do well in mathematics? }\end{array}$} & $72.1 \%$ & $25.8 \%$ & $1.6 \%$ & $0.5 \%$ \\
\hline & \multicolumn{4}{|c|}{ Self-report } \\
\hline & A & $\mathrm{B}$ & $\mathrm{C}$ & $\mathrm{D}$ \\
\hline $\begin{array}{l}\text { The grade I usually get in mathematics } \\
\text { class is: }\end{array}$ & $32.8 \%$ & $51.1 \%$ & $16.1 \%$ & $0 \%$ \\
\hline
\end{tabular}

The MPS uses a Likert-type scale wherein the subjects respond, on a scale of 1-7, to their degree of agreement with a statement. Pre-service teachers rated each of the first 33 questions on a 7-point scale with 1 being "Strongly agree", 4 being "Neutral", and 7 being "Strongly disagree". The questionnaire contained questions related to pre-service teachers' perceptions of what mathematics is and how to do well in it, what mathematics solutions should be, how mathematics problems can be solved, how mathematics should be taught, and how mathematics is learned, mathematics genius to do mathematics, nature of school mathematics, and student motivation. Table 4 shows mean scores of responses of the MPS. 
Table 4

Mean of Responses of MPS $(N=68)$

\begin{tabular}{|c|c|c|}
\hline Category & Item No. & Mean \\
\hline \multirow{4}{*}{ 1. What mathematics is? } & 1 & 3.63 \\
\hline & 2 & 2.66 \\
\hline & 3 & 3.55 \\
\hline & 31 & 3.96 \\
\hline \multirow{3}{*}{ 2. How to do well in it? } & 14 & 4.13 \\
\hline & 28 & 4.01 \\
\hline & 32 & 4.40 \\
\hline \multirow{4}{*}{ 3. What mathematics solutions should be? } & 4 & 4.83 \\
\hline & 5 & 3.50 \\
\hline & 6 & 3.96 \\
\hline & 15 & 5.19 \\
\hline \multirow{4}{*}{ 4. How mathematics problems can be solved? } & 11 & 5.83 \\
\hline & 12 & 4.01 \\
\hline & 13 & 4.77 \\
\hline & 17 & 4.73 \\
\hline \multirow{2}{*}{ 5. How mathematics should be taught? } & 7 & 1.68 \\
\hline & 8 & 2.04 \\
\hline \multirow{3}{*}{6. How mathematics is learned? } & 10 & 3.01 \\
\hline & 16 & 4.74 \\
\hline & 27 & 2.88 \\
\hline \multirow{2}{*}{ 7. Mathematics genius to do mathematics } & 30 & 5.7 \\
\hline & 33 & 2.85 \\
\hline \multirow{2}{*}{ 8. Nature of school mathematics } & 26 & 4.72 \\
\hline & 29 & 5.45 \\
\hline \multirow{4}{*}{ 9a. Student motivation (positive) } & 18 & 3.84 \\
\hline & 20 & 2.27 \\
\hline & 21 & 3.68 \\
\hline & 24 & 4.23 \\
\hline \multirow{3}{*}{ 9b. Student motivation (negative) } & 19 & 3.03 \\
\hline & 22 & 4.66 \\
\hline & 23 & 4.39 \\
\hline \multirow{2}{*}{ 10. Other items } & 9 & 5.01 \\
\hline & 25 & 6.04 \\
\hline
\end{tabular}

According to the data, Category 1 containing items 1, 2, 3, and 31 presents the pre-service elementary school teachers' perceptions of what mathematics is; the mean scores for items 1, 2, 3, and 31 were 3.63, 2.66, 3.55, and 3.96 respectively. The data indicate that pre-service elementary school teachers considered a perception of mathematics that is a set collection of facts, rules, procedures, and formulas to be memorized. In addition, Garofalo (1998) and Hembree (1990) reported the potentially undesired influence of negative attitude and perceptions on student performance in mathematical tasks, and on their cognition. 
Category 2 containing items 14, 28, and 32 presents how to do well in mathematics; the mean scores for items 14,28 , and 32 were $4.13,4.01$, and 4.40 respectively. The results also revealed that pre-service elementary school teachers seem to neutrally think that the best way to do well in mathematics is to memorize the material and must be good at arithmetic. This is hardly the most creative or logical of acts, if one is a creative discipline in mathematics one can discover, and learn to be logical. Mathematics methods courses should provide pre-service teachers with learning opportunities in which they experience the excitement that comes from making sense of mathematics instead of memorizing formulas and rules. This focus on making sense of mathematics is an essential component of the reform movement in mathematics education.

Category 3 containing items $4,5,6$, and 15 presents what mathematics solutions should be; the mean scores for items 4, 5, 6, and 15 were 4.83, 3.50, 3.96, and 5.19 respectively. The results revealed that pre-service elementary school teachers do not agree viewing problem-solving as looking for right answers. The reformed mathematics curriculum also values problems that do not looking for right answers only as long as they contribute to students' conceptual understanding.

Category 4 containing items $11,12,13$, and 17 presents how mathematics problems can be solved; the mean scores for items $11,12,13$, and 17 were 5.83, 4.01, 4.77, and 4.73 respectively. Pre-service elementary school teachers seem to believe that solving mathematics problems depends on knowing the rule. Mathematics is presumed to be bound by bound and problem-solving is recognized as an essential goal in mathematics education. But the pre-service elementary school teachers did not support the idea that there is only one correct way to solve a mathematics problem. In addition, the pre-service elementary school teachers determined good mathematics teachers to be the one showing students lots of ways for solving the same question, and indicated that students can get the correct answer to a mathematics problem using methods other than the teacher or the textbook uses.

Category 5 containing items 7 and 8 presents how mathematics should be taught; the mean scores for items 7 and 8 were 1.68 and 2.04 respectively. According to items 7 and 8, pre-service elementary school teachers believe that good teaching practice in mathematics consists of showing students lots of different ways to look at the same question. On the other hand, students also think that good teaching practice consists of showing students lots way to answer the mathematics questions they will be tested on. Some evidence exists to suggest that pre-service elementary school teachers' perceptions of good teachers were related to being shown how to solve problems. One possible reason of these inconsistent views could be that although several reformist changes have been made on the reformed curriculum, students in schools are still being assessed through traditional written exams and high-stakes tests are still of an important concern for students at all levels.

Category 6 containing items 10,16 , and 27 presents how mathematics is learned; the mean scores for items 10, 16, and 27 were 3.01, 4.74, and 2.88 respectively. According to items 10 and 27, pre-service elementary school teachers believed that in mathematics you can be creative and discover things by yourself.

Category 7 containing items 30 and 33 presents mathematics genius to do mathematics; the mean scores for items 30 and 33 were 5.7 and 2.85 respectively. From items 30 and 33, there is a contradiction between the two items if the former refers to born with mathematics ability to do well in mathematics and the latter refers some people are good at mathematics and some are not. Pre-service elementary school teachers generally believe that some people are just good at mathematics.

Category 8 containing items 26 and 29 presents the nature of school mathematics; the mean scores for items 26 and 29 were 4.72 and 5.45 respectively. Based on the means of items 26 and 29, the data show that 
pre-service teachers "Strongly agree" that school mathematics is useful in real life and different mathematics courses covered related topics, because they may be more preoccupied with learning as an in itself rather than being concerned with self-perceptions.

Category 9a containing items 18, 20,21, and 24 presents student positive motivation; the mean scores for items $18,20,21$, and 24 were $3.84,2.27,3.68$, and 4.23 respectively. The data show that pre-service elementary school teachers do not agree that the subject matter is interesting, and that learning the discipline will help them think clearly. Pre-service elementary school teachers generally wanted to do well in mathematics, because they want teachers think that they are good students. It shows that pre-service elementary school teachers tended to get in terms of extrinsic reward. In addition, Category $9 \mathrm{~b}$ containing items 19, 22, and 23 presents student negative motivation; the mean scores for items 19,22 , and 23 were $3.35,4.66$, and 4.39 respectively. The pre-service elementary school teachers claim not to be motivated by the fear of looking stupid; but neither have they believed if they do not try to learn mathematics, they will get in trouble.

\section{Conclusion and Implications}

In summary, the beliefs pre-service elementary school teachers reflected in the instrument items were in line with the current reform movements in mathematics education. The pre-service elementary school teachers generally indicated positive beliefs to the questionnaire items about mathematics. For instance, they gave importance to appreciate developing different ways of solutions to the same problem, why a solution to a mathematics problem works, think in mathematics can be creative and discover things by themselves, and apply mathematics knowledge and skills to real life. However, the results revealed that the pre-service elementary school teachers held several moderate and negative beliefs. The data indicate that pre-service teachers' definition of mathematics reflects more of a subject that is all about symbols, notations, equations, formulas, and procedures that are to be memorized. Certain beliefs about mathematics are shared by pre-service teachers. When these are restricted, narrow, and unimaginative, the way in which mathematics is taught and assessed will also be restricted, narrow, and unimaginative. This approach is entirely opposed to the view that considers problem-solving as the key to mathematics. In mathematical problem-solving, emphasis is placed on thinking skills, the use of both inductive and deductive reasoning, on being creative and adventurous in approach to the mathematical situation. These results suggest that mathematics educators must help pre-service teachers understand and value the need for perseverance in solving mathematics problems; and help students realize the connections between the mathematics they learn in school and the mathematics-related fields that might interest them. Instead of focusing on formulas and rules, mathematics teachers should help their students make sense of the mathematics they are learning.

The data show that pre-service elementary school teachers "Strongly agree" that mathematics helped them think logically and that mathematics was mostly memorizing formulas and rules. These responses would seem to be in conflict with each other. How does memorization contribute to the development of logical thought? Are students equating a set of steps in completing an algorithm with logical thought? Pre-service teachers have learned in schools that mathematics helps them think logically, but they may not really understand what this means. Although they know that mathematics is logical, all they understand of mathematics is memorization. In either case, mathematics educators need to engage pre-service elementary school teachers in non-routine problem-solving experiences in which they need to reason their way to a solution. The results also revealed that pre-service elementary school teachers do not agree that the subject matter is interesting, and that learning the 
discipline will help them think clearly. A student's motivation and degree of interest is a significant factor that influences learning (Hidi \& Harackiewicz, 2000). Motivation is among the most powerful determinants of students' success or failure in school (Hardre, Crowson, DeBacker, \& White, 2007). Therefore, a student's own lack of interest can deter understanding (Koller, Baumert, \& Schnabel, 2001). This means that one needs to address his/her beliefs and behaviors before introducing mathematical concepts and expecting meaningful learning in class.

Mathematics educators also need to develop pre-service teachers' motivation towards mathematics. Motivation is a critical issue in learning and its role in mathematics learning cannot be underestimated. The emphasis on investigating mathematical situations or solving problems, especially if they are ones which are relevant for the students, could well be the key to motivation in mathematics. Helping pre-service teachers' realize these types of connections between the mathematics they are learning in school and its applications in their future classroom is also strongly encouraged by the reform movement.

\section{References}

Ball, D. L. (1988). Unlearning to teach mathematics. For the Learning of Mathematics, 8(1), 40-48.

Ball, D. L., \& Bass, H. (2000). Interweaving content and pedagogy in teaching and learning to teach: Knowing and using mathematics. In J. Boaler (Ed.), Multiple perspectives on the teaching and learning of mathematics (pp. 83-104). Westport, C.T.: Ablex.

Battista, M. T. (1994). Teachers beliefs and the reform movement in mathematics education. Phi Delta Kappan, 75, 462-463.

Garofalo, J. (1998). Beliefs and their influence on mathematics performance. Mathematics Teacher, 83, 502-505.

Hardre, P. L., Crowson, H. M., DeBacker, I., \& White, D. (2007). A multi-theory study of high school students' beliefs, perceptions, goals and academic motivation. Journal of Experiential Education, 75(4), 247-269.

Hembree, R. (1990). The nature, effects, and relief of mathematics anxiety. Journal for Research in Mathematics Education, 21(1), 33-46.

Hidi, S., \& Harackiewicz, J. M. (2000). Motivating the academically unmotivated: A critical issue for the 21 the century. Review of Educational Research, 70, 151-179.

Hill, H., Schilling, S. G., \& Ball, D. L. (2004). Developing measures of teacher' mathematics knowledge for teaching. The Elementary School Journal, 105, 11-30.

Koller, O., Baumert, J., \& Schnabel, K. (2001). Does interest matter? The relationship between academic interest and achievement in mathematics. Journal for Research in Mathematics Education, 32(5), 448-470.

Lester, F. K. (1994). Musings about mathematical problem solving research: 1970-1994. Journal for Research in Mathematics Education, 25(6), 660-675.

Lampert, M. (1990). When the problem is not the question and the solution is not the answer: Mathematical knowing and teaching. American Educational Research Journal, 27(1), 29-64.

Ma, L. (2010). Knowing and teaching elementary mathematics: Teachers' understanding of fundamental mathematics in China and the United States (10th anniversary ed.). Mahwah, N.J.: Lawrence Erlbaum Associates.

McLeod, D. B. (1989). Beliefs, attitudes, and emotions: New view of affect in mathematics education. In D. B. McLeod, \& V. M. Adams (Eds.), Affect and mathematical problem solving: A new perspective (pp. 245-258). New York, N.Y.: Springer Verlag.

National Council of Teachers of Mathematics (NCTM). (2000). Principles and standards for school mathematics. Reston, V.A.: NCTM.

Resnick, L. (1987). Education and learning to think. Washington, D.C.: National Academy Press.

Sam, L. C. (2002). Public images of mathematics. Philosophy of Mathematics Education Journal, 15, 15.

Schoenfeld, A. H. (1992). Learning to think mathematically: Problem solving, metacognition, and sense making in mathematics. In D. A. Grouws (Ed.), Handbook of research on mathematics teaching and learning (pp. 334-369). New York, N.Y.: Macmillan.

Schoenfeld, A. (1989). Explorations of students' mathematical beliefs and behavior. Journal for Research in Mathematics Education, 20(4), 338-355. 
Sowder, J. T., \& Schappelle, B. P. (Eds.). (1995). Providing a foundation for teaching mathematics in the middle grades. Albany, N.Y.: State University of New York Press.

Swars, S. L. (2006). Examining perceptions of mathematics teaching effectiveness among elementary pre-service teachers with differing levels of mathematics teacher efficacy. Journal of Instructional Psychology, 32(2), 139-247.

Thompson, A. (1992). Teachers' beliefs and conceptions: A synthesisof the research. In D. A. Grouws (Ed.), Handbook of research on mathematics teaching and learning (pp. 127-146). Englewood Cliffs, N.J.: Prentice Hall International.

Tobias, S. (1993). Overcoming math anxiety. New York, N.Y.: W.W. Norton \& Company.

Vinter, A. (1999). How meaning modifies drawing behavior in children. Child Development, 70(1), 33-49. Retrieved September 13, 2008, from http://www.jstor.org/stable/1132013 